\title{
APLICAÇÃO DO PROCESSO OXIDATIVO AVANÇADO ELETROQUIIMICO PARA OXIDAÇÃO E DEGRADAÇÃO DE CORANTES PRESENTES EM EFLUENTE TEXTIL SIMULADO
}

\author{
K. S. de ARAÚJO ${ }^{1}$, T. M. FLORÊNCIO ${ }^{1}$, A. C. G. MALPASS ${ }^{1}$ e G. R. P. MALPASS ${ }^{1}$ \\ ${ }^{1}$ Universidade Federal do Triângulo Mineiro, Instituto de Ciências Tecnológicas e Exatas, \\ Departamento de Engenharia Química \\ E-mail para contato: k.s.araujo@gmail.com
}

\begin{abstract}
RESUMO - O descarte de considerável concentração de corantes sintéticos no meio ambiente causa problemas com a legislação, além de preocupação pública, o que configura importante desafio para a comunidade científica envolvida com problemas ambientais. Tais corantes, devido à sua origem e complexa estrutura, são difíceis de serem degradados constituindo objeto no desenvolvimento de Processos Oxidativos Avançados (POA) para aplicação no tratamento de águas residuais. Dessa maneira, estudou-se a oxidação/degradação de diferentes classes de corantes por POA através da técnica eletrocatalítica. Utilizou-se uma célula eletroquímica com eletrodos de trabalho de $\mathrm{Ti} / \mathrm{Ru}_{0,3} \mathrm{Ti}_{0,7} \mathrm{O}_{2}$, contra-eletrodos de $\mathrm{Ti}$, eletrólito suporte de Cloreto de Sódio e como referência, Eletrodo Padrão de Hidrogênio. As análises químicas para monitoração dos valores obtidos antes e depois do tratamento do efluente têxtil simulado foram Demanda Química de Oxigênio (DQO), Carbono Orgânico Total (COT), Espectroscopia na região do UV-visível e Testes de fitotoxicidade. Verificou-se redução de DQO de $86 \%$ após 300 minutos e de COT de $92 \%$ após 90 minutos, mediante aplicação da técnica eletrocatalítica com irradiação UV. Conclui-se que através da redução dos indicadores de qualidade da água (DQO e COT) a eficiência da técnica eletrocatalítica foto-assistida foi comprovada quantitativamente e qualitativamente.
\end{abstract}

\section{INTRODUÇÃO}

A contaminação de águas por corantes sintéticos gera impactos ambientais, sendo este problema um desafio para a comunidade científica no que diz respeito ao desenvolvimento de tecnologias ecologicamente corretas de tratamento. A aplicação do método de tratamento envolve dois alvos específicos, tais como a eficiência na oxidação/degradação do poluente e os baixos custos de instalação/operação.

Como os corantes são difíceis de serem degradados devido à sua complexa estrutura e origem sintética, constituem objeto de grande interesse no desenvolvimento de Processos Oxidativos Avançados (POAs) para aplicação no tratamento de águas residuais. Os POAs objetivam a produção de radicais hidroxila $\left({ }^{\bullet} \mathrm{OH}\right)$, espécies altamente oxidativas, e por isso 
podem ser encarados como processos aliados aos Doze Princípios de Química Verde no que tange ao uso da catálise (MARTÍNEZ-HUITLE, BRILLAS, 2009).

Neste trabalho, utilizou-se a técnica eletrocatalítica fotoassistida, uma associação de POAs para atuar no tratamento do efluente têxtil simulado visando aumentar a eficiência de degradação do poluente, conforme mostra a Figura 1. Trata-se da combinação dos processos eletroquímico e fotoquímico na presença de catalisador. No caso dos corantes utilizados na indústria química que permanecem no efluente industrial, tal poluente é degradado através do emprego de uma célula com eletrodos anódicos e catódicos, aplicando-se uma diferença de potencial (ddp) no ânodo, formado por uma base de metal inerte e coberto por um filme de metal com ação catalítica.

Figura 1 - Eletrocatálise Fotoassistida

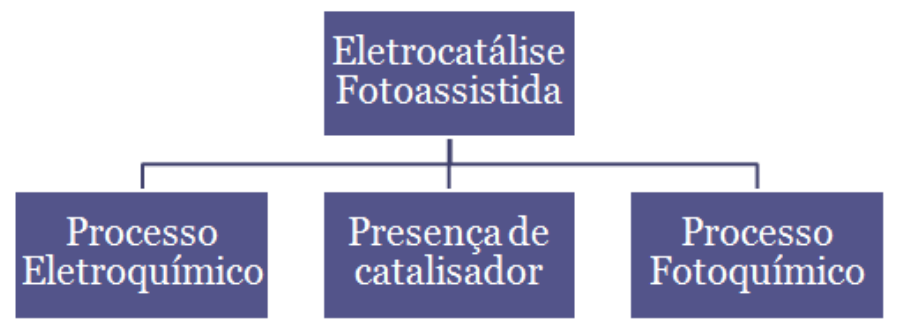

Para a degradação ocorrer a taxas significativas torna-se necessário acrescentar cloreto de sódio $(\mathrm{NaCl})$ a mistura da reação (MARTÍNEZ-HUITLE, BRILLAS, 2009). Esta medida aumenta a condutividade e gera íons hipoclorito, o que aumenta a eficiência da degradação, segundo as Equações de 1 a 3.

$$
\begin{aligned}
& 2 \mathrm{Cl}^{-} \rightarrow \mathrm{Cl}_{2}+2 e^{-} \\
& \mathrm{Cl}_{2}+\mathrm{H}_{2} \mathrm{O} \rightarrow \mathrm{HOCl}+\mathrm{HCl} \\
& \mathrm{HOCl} \rightarrow \mathrm{OCl}^{-}+\mathrm{H}^{+}
\end{aligned}
$$

Em estudos anteriores verificou-se que o uso de sais de cloreto de sódio $(\mathrm{NaCl})$ como eletrólito suporte no processo, e o emprego de irradiação ultravioleta (UV), diminuem a formação de organoclorados e reduz portanto a toxicidade dos produtos finais observados. Em outros estudos foram mostrados que a fitotoxicidade (organismo teste: Lactuca sativa) de soluções de efluente têxtil é reduzida usando $\mathrm{NaCl}$ como eletrólito. Provavelmente isso se deve a produção de radicais hidroxila $\left({ }^{\bullet} \mathrm{OH}\right)$ durante a fotólise de espécies de cloro livre, como pode ser observado nas Equações 4 e 5 (MALPASS et. al, 2011).

$$
\begin{aligned}
& \mathrm{OCl}^{-}+h v \rightarrow{ }^{\bullet} \mathrm{O}^{-}+{ }^{\bullet} \mathrm{Cl} \\
& \bullet^{-}+\mathrm{H}_{2} \mathrm{O} \rightarrow{ }^{\bullet} \mathrm{OH}^{-}+\mathrm{OH}^{-}
\end{aligned}
$$

\section{OBJETIVO}


Este trabalho teve como objetivo estudar a degradação de diferentes classes de corantes por processos oxidativos avançados através da técnica eletrocatalítica com e sem irradiação UV, observando os princípios da Química Verde e os interesses ambientais.

\section{METODOLOGIA}

Para os ensaios eletroquímicos, foi utilizada uma célula eletroquímica e para circulação de água visando à estabilidade da temperatura, usou-se um banho termostático de acordo com a Figura 2. Os eletrodos de trabalho empregados, ânodos dimensionalmente estáveis $(\mathrm{ADE})$, foram discos $(\Phi=1 \mathrm{~cm})$ de $\mathrm{Ti} / \mathrm{Ru}_{0,3} \mathrm{Ti}_{0,7} \mathrm{O}_{2}$ e Contra-eletrodos de Ti. Como eletrólito suporte, utilizou-se Cloreto de Sódio $(\mathrm{NaCl})$ 0,3 M. Como referência, utilizou-se Eletrodo Reversível Hidrogênio (ERH).

Empregou-se fonte luminosa ultravioleta inserida diretamente na célula. Os ensaios foram realizados sob corrente aplicada de 1,5 A durante 90 minutos, com e sem irradiação UV, recolhendo-se amostras em intervalos de 15 minutos. O efluente têxtil simulado foi preparado com os reagentes e composições mostrados na Tabela 1. Os corantes utilizados no efluente simulado foram doados pela empresa Aupicor Química localizada em Pomedore/SC.

As análises químicas para monitoração dos valores obtidos antes e depois do tratamento foram Demanda Química de Oxigênio (DQO), Carbono Orgânico Total (COT), Espectroscopia na região do UV-visível e Testes de fitotoxicidade segundo protocolo ASTM utilizando sementes de alface (Lactuca sativa). As análises de DQO foram realizadas em efluentes tratados após 90 e 300 minutos, e as análises de COT foram realizadas em amostras submetidas a tratamento de 90 minutos.

Figura 2 - Célula Eletroquímica e Banho Termostático
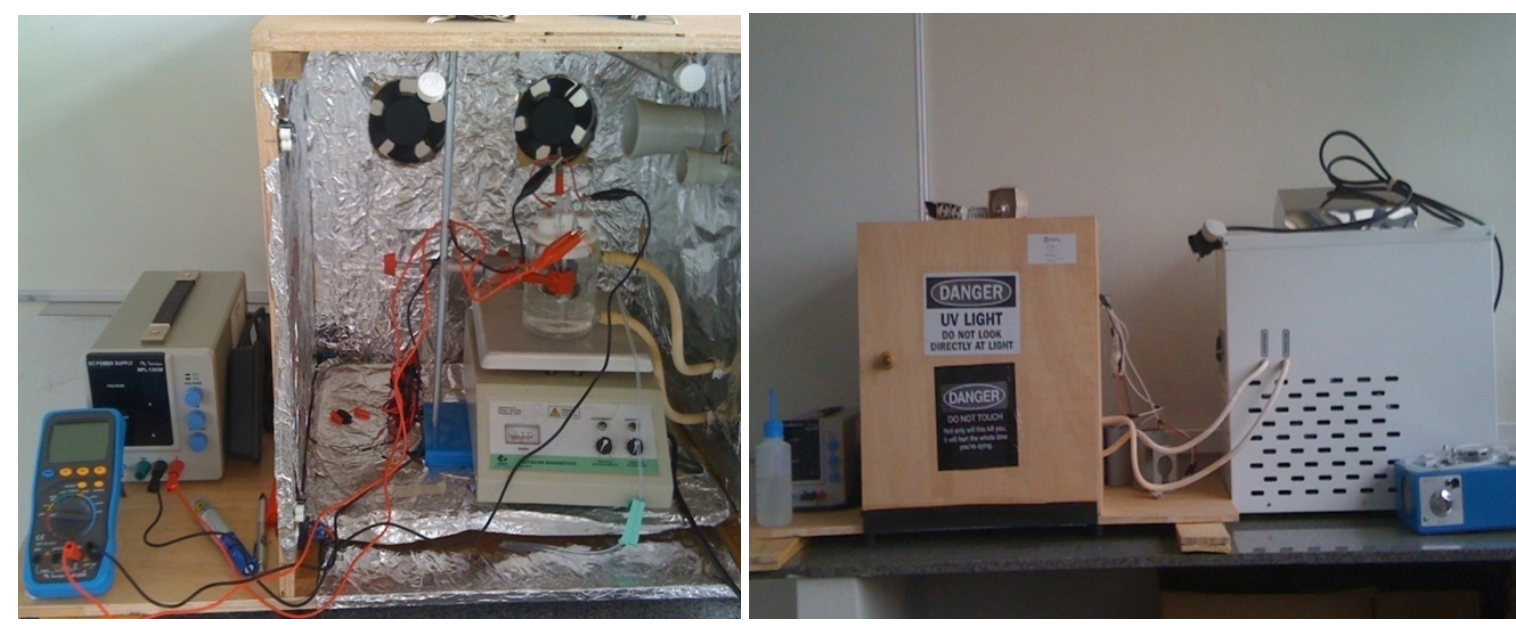
Tabela 1 - Composição do Efluente Têxtil Simulado.

\begin{tabular}{cc}
\hline Sistema & $\begin{array}{c}\text { Concentração } \\
(\mathrm{mg} / \mathrm{L})\end{array}$ \\
\hline Laranja Tiafix ME2RL & 25 \\
Amarelo Tiafix ME4GL & 25 \\
Azul Tiafix MERF & 25 \\
150\% & 25 \\
Vermelho Tiafix & 100 \\
ME6BL & 100 \\
$\mathrm{NaOH}$ & 200 \\
$\mathrm{Na}_{2} \mathrm{CO}_{3}$ & $17532 *$ \\
$\mathrm{Amaciante}$ & \\
$\mathrm{NaCl}$ &
\end{tabular}

* equivalente a $0,3 \mathrm{M} \mathrm{NaCl}$

\section{RESULTADOS}

As análises de Demanda Química de Oxigênio (DQO) foram realizadas pelo método colorimétrico em refluxo fechado e a leitura em espectrofotômetro, para os tempos de 90 e 300 minutos. As análises de Carbono Orgânico Total (COT) foram realizadas pelo método padrão através do Analisador de Carbono Orgânico Total, para um tempo de 90 minutos. Os dados de DQO e COT encontram-se na Tabela 2, e os dados de eficiência de redução (\%) encontram-se na Tabela 3.

Tabela 2: Dados de DQO e COT obtidos para o efluente bruto e tratado.

\begin{tabular}{cccc}
\hline & $\mathrm{DQO}\left(\mathrm{mg} \mathrm{O}_{2} / \mathrm{L}\right)$ & $\mathrm{DQO}\left(\mathrm{mg} \mathrm{O}_{2} / \mathrm{L}\right)$ & COT $(\mathrm{ppm})$ \\
& 300 Minutos & 90 minutos & 90 minutos \\
\hline Efluente Bruto & 2712,85 & $2.712,85$ & 34,97 \\
Sem UV & 744,43 & 701,6 & 13,37 \\
Com UV & 383,34 & 432,65 & 2,85 \\
\hline
\end{tabular}

Tabela 3: Eficiência do tratamento eletroquímico com e sem irradiação UV.

\begin{tabular}{cccc}
\hline & $\begin{array}{c}\text { Eficiência Redução } \\
\text { (\%) DQO } \\
\text { 300 Minutos }\end{array}$ & $\begin{array}{c}\text { Eficiência Redução } \\
(\%) \text { DQO } \\
90 \text { minutos }\end{array}$ & $\begin{array}{c}\text { Eficiência Redução } \\
(\%) \text { COT } \\
90 \text { minutos }\end{array}$ \\
\hline Sem UV & 73 & 74 & 62 \\
Com UV & 86 & 84 & 92 \\
\hline
\end{tabular}

Verifica-se que após 90 minutos de aplicação da técnica eletrocatalítica sem irradiação UV, a redução de DQO foi de $74 \%$, enquanto que após 300 minutos essa redução foi de $73 \%$. Para a aplicação desta técnica com irradiação UV obteve-se uma redução de DQO maior, sendo $84 \%$ após 90 minutos e $86 \%$ após 300 minutos. Em relação ao COT, após 90 minutos foi alcançada uma redução de $62 \%$ utilizando a técnica eletrocatalítica sem irradiação UV, e quando aplicou-se esta técnica com irradiação UV essa redução foi maior, sendo de $92 \%$. 
Estes resultados de DQO e COT evidenciaram a eficiência da técnica eletrocatalítica fotoassistida.

O processo de degradação eletroquímica pode se observado visualmente na Figura 3, sendo que antes do tratamento o efluente têxtil simulado apresentava cor roxa e após o tratamento eletroquímico fotoassistido este efluente ficou incolor.

Figura 3 - Efluente têxtil simulado antes e após a degradação eletroquímica

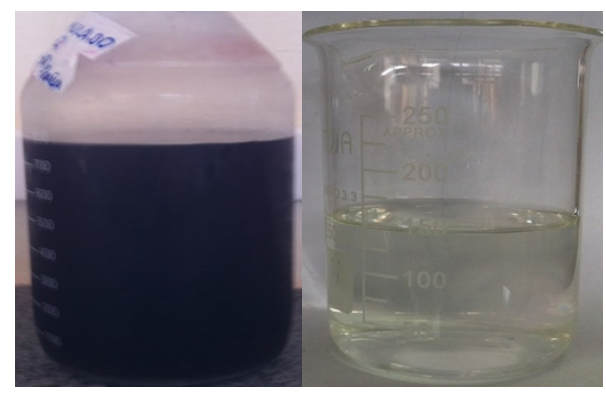

Os espectros de absorbância dos efluentes bruto e tratado, mediante aplicação da técnica eletrocatalítica sem e com irradiação UV, mostraram um comportamento de crescimento da absorção na região de $290 \mathrm{~nm}$, com uma tendência para aumento mais significativo mediante tratamento sob irradiação UV, de acordo com a Figura 4. Tal crescimento deve-se à presença de hipoclorito. Nesta figura, tem-se C1 o efluente bruto 81\% diluído, C2 94\% diluído e C3 97\% diluído. O efluente tratado sem e com irradiação UV foi 97\% diluído.

Figura 4 - Espectros de absorbância dos efluentes bruto e tratado mediante aplicação da técnica eletrocatalítica sem e com irradiação UV

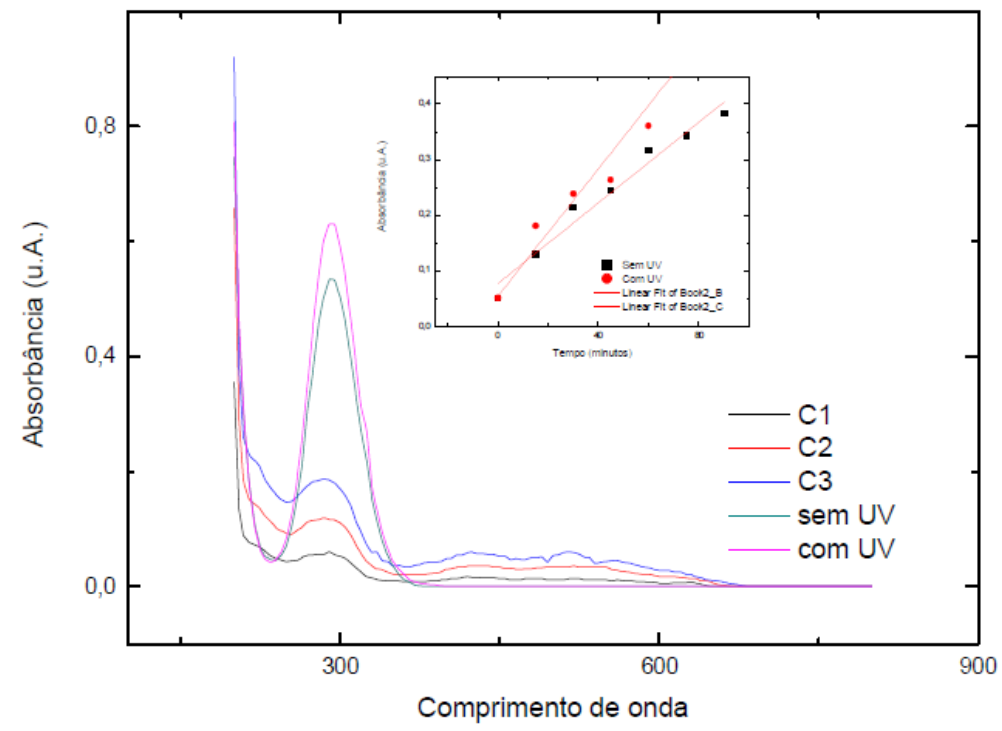

Os testes de fitotoxicidade do resíduo tratado foram realizados segundo protocolo ASTM utilizando sementes de alface (Lactuca sativa) como organismo-teste, para avaliar a formação de novos compostos potencialmente poluentes. A fitotoxicidade de soluções do efluente têxtil foi reduzida usando $\mathrm{NaCl}$ como eletrólito. Este resultado deve-se à produção de 


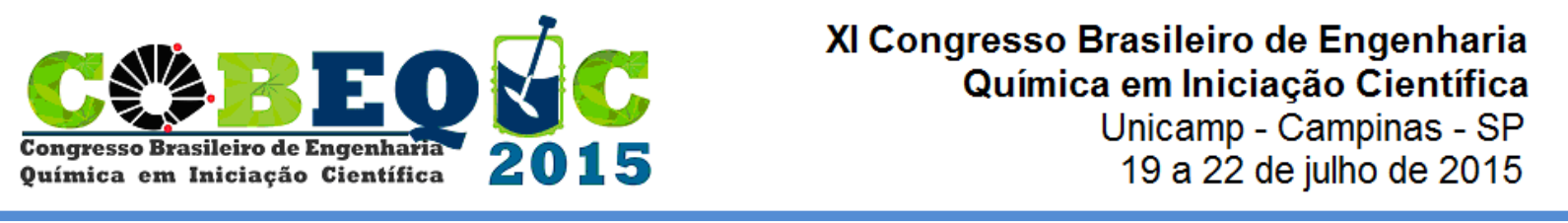

radicais hidroxilas $\left({ }^{\bullet} \mathrm{OH}\right)$ durante a fotólise de espécies de cloro livre. Porém, torna-se necessário realizar mais ensaios para explorar melhor os resultados, visto que o estudo da fitoxicidade dos efluentes ainda não foi concluído.

\section{CONCLUSÃO}

Neste estudo de degradação de corantes por processos oxidativos avançados através da técnica eletrocatalítica com e sem irradiação UV observou-se a redução dos indicadores de qualidade da água, Demanda Química de Oxigênio (DQO) e Carbono Orgânico Total (COT). Dessa maneira, verificou-se a eficiência da técnica eletrocatalítica foto-assistida comprovada quantitativamente e qualitativamente. A partir dos resultados obtidos conclui-se que a eletrocatálise foto-assistida pode ser utilizada como uma alternativa para a degradação de corantes têxteis, visto que houve alta eficiência na remoção de COT e DQO.

\section{REFERÊNCIAS}

MALPASS, G.R.P.; MIWA, D.W. ; SANTOS, R.L. ; VIEIRA, E.M. ; MOTHEO, A.J. . Unexpected toxicity decrease during photoelectrochemical degradation of atrazine with $\mathrm{NaCl}$. Environmental Chemistry Letters (Print), v. 1, p. 1, 2011.

MARTÍNEZ-HUITLE, C.A.; BRILLAS, E. Decontamination of wastewaters containing synthetic organic dyes by methods: A general review. Applied Catalysis B: Environmental, v.87, p.105-145. 2009. 